\section{Omission training: Effects of gradual introduction}

\section{JEFF S. TOPPING, * OSMO K. LARMI, and DENNIS L. JOHNSON \\ Mississippi State University, State College, Miss. 39762}

Pigeons were initially trained on a VI 30-sec reinforcement schedule and then either gradually or immediately switched to the final and maximum parameter values of an omission training schedule. Results indicated that the gradual introduction procedure was more efficient since it produced significantly faster elimination of the pecking response.

Primarily because of its relevance for the modification of behavior, much research attention has recently been focused on the procedure known as omission training (OT), in which Ss are reinforced for omitting a previously reinforced response. Specifically, investigations (cf. Topping, Pickering, \& Jackson, 1971a, 1972; Uhl \& Garcia, 1969; Uhl \& Sherman, 1971; Zeiler, 1971) have been concerned with comparing the "powers" of OT with the more traditional response-elimination methods of extinction (ET) and punishment. Despite some differences in findings, all of these studies have shown that OT can be an effective method of response elimination, especially regarding the durability of the effects.

The present study utilized findings from earlier work on discrimination learning. in an attempt to further increase the effectiveness of OT. Schlosberg \& Solomon (1943) and Lawrence (1952) have demonstrated that faster learning of a simultaneous discrimination occurs when differences between stimuli are gradually reduced as opposed to being presented at the constant final difference. Terrace's (1963) "errorless" technique also shows the importance of progressively exposing Ss to the final discrimination.

Based on these results, this experiment was designed to examine the effectiveness of gradually increasing the parameter values during OT to their maximum as opposed to introducing the maximum values immediately.

\section{SUBJECTS}

The Ss were eight experimentally naive male White King pigeons, individually housed, and maintained at approximately $75 \%$ of their ad lib weights throughout the experiment.

\section{APPARATUS}

$A$ standard three-key pigeon chamber, $49.5 \times 35.5 \times 35.5 \mathrm{~cm}$, was located within a sound-attenuating

*Supported in part by NSF Trainee Grant R200X-9100 to the senior author. Requests for reprints should be sent to Jeff $S$. Topping. P.O. Drawer PF, Mississippi State University, State College, Miss. 39762. ventilated cubicle. The 2.5 -cm-diam keys were centered, $25.4 \mathrm{~cm}$ from the floor and $10 \mathrm{~cm}$ apart, on the display panel. Only the center key was employed in the present study, and the remaining keys were covered by metal plates. A minimum force of $0.15 \mathrm{~N}$ was required to operate the key, and responses produced auditory feed b a c . The key was transilluminated by white light and the experimental chamber was diffusely lighted from above by two small lamps. A $5-\mathrm{cm}$ square opening, centered $7.6 \mathrm{~cm}$ from the bottom of the display panel, functioned as the food aperture. Reinforcement consisted of a 3.5 -sec access to the illuminated aperture, which contained Purina Hen Chow. A white-noise generator operated to mask extraneous noises, and a blower regulated the temperature inside the chamber. In addition, a one-way mirror was located in the side of the chamber to permit observation of the S's behavior. A system of electromechanical programming equipment was located in a separate room and was used to control the apparatus and record the data.

\section{PROCEDURE}

As soon as Ss were reduced to $75 \%$ of their ad lib weights, they were given 2 days of magazine training, during which 60 reinforcements were delivered daily according to a variable-time (VT) $30-$ sec schedule. During the next 3 days, Ss were shaped (CRF) to peck the response key and allowed to make 60 continuously reinforced responses daily. Ss were then gradually introduced to a VI 30 -sec schedule, and response rates on this schedule were stabilized over the course of the next 21 dail' sessions. All sessions on the VI $30-\mathrm{sec}$ schedule were terminated after 60 reinforcements had been produced.

Following training on the VI $30-\mathrm{sec}$ schedule, Ss were split into two equivalent groups and exposed to OT. Four of the Ss were switched immediately (Group I) to an OT 30-sec schedule. That is, reinforcement was always contingent on omitting the pecking responsefor $30 \mathrm{sec}$, each pecking response postponed reinforcement for $30 \mathrm{sec}$, and reinforcement occurred every $30 \mathrm{sec}$, provided no pecking responses were emitted. The remaining Ss were switched initially to an OT 2-sec schedule, with the OT value being gradually (Group G) increased to $30 \mathrm{sec}$. The gradual increases occurred in 2-sec intervals, with the criterion for increase being three or fewer pecking responses in the course of five consecutive reinforcements. Omission training continued for 10 days for all Ss, with daily sessions terminating after $35 \mathrm{~min}$ or 60 reinforcements, whichever occurred first.

After completion of OT, a durability test of response elimination was conducted. That is, all Ss were returned to a VT 30 -sec schedule for four daily 30-min sessions.

RESULTS AND DISCUSSION

Table 1 presents the mean absolute response rates during the final three VI sessions for each $S$, as well as the individual response rates during the OT and durability testing sessions. Response rates during OT and durability testing were transformed by the shape-function technique of Anderson (1963). This transformation treated each S's daily response rate as a proportion of his mean response rate during the final three VI sessions; i.e., a transformed value of 1 indicates responding at the same rate as at the end of VI training and a value of 0 indicates complete or nearly complete cessation of the pecking response. Regarding Group G, all four Ss reached the OT 30 -sec value during the latter portion of the third day of training. Thus, in Table 1 , only Days 4-10 represent complete sessions on OT 30 sec for Ss in Group G.

A Groups by Days analysis of variance was performed on the OT data from Day 4 to Day 10 in Table 1. This analysis yielded significant groups $(F=21.75$, df $=1 / 6, p<.01)$ and days $(F=63.00, \mathrm{df}=6 / 36, p<.001)$ main effects, indicating, respectively, that Group G emitted proportionately fewer pecking responses on the OT 30-sec schedule than Group I and that responding decreased as training progressed. In addition, the Groups by Days interaction was significant $(F=$ 56.00, $\mathrm{df}=6 / 36, \mathrm{p}<.001$ ), reflecting that Group I decreased pecking considerably over Days 4-10, especially from Day 4 to Day 6, whereas Group $G$ made virtually no pecking responses at all during this time. Subsequent tests of simple main effects showed significant $(p<.01)$ differences between the groups on Days 4 and 5 only.

A similar analysis of variance on the data for the 4 days of durability 
Table 1

Individual Transformed Response Rates

\begin{tabular}{|c|c|c|c|c|c|c|c|c|c|c|c|c|c|c|c|c|}
\hline & \multirow[b]{2}{*}{$\mathbf{S}$} & \multirow{2}{*}{$\begin{array}{c}\text { Mean VI } \\
\text { Response } \\
\text { Rate } \\
\text { (R/Min) }\end{array}$} & \multicolumn{10}{|c|}{ Omission Training (Days) } & \multicolumn{2}{|c|}{ Durability } & \multicolumn{2}{|c|}{ Testing } \\
\hline & & & 1 & 2 & 3 & 4 & $\mathbf{5}$ & 6 & 7 & 8 & 9 & 10 & 1 & 2 & $\mathbf{3}$ & 4 \\
\hline Group $\mathbf{G}$ & $\begin{array}{r}12 \\
10 \\
11 \\
4\end{array}$ & $\begin{array}{r}110 \\
93 \\
86 \\
70\end{array}$ & $\begin{array}{l}.12 \\
.12 \\
.40 \\
.24\end{array}$ & $\begin{array}{l}.05 \\
.06 \\
.09 \\
.11\end{array}$ & $\begin{array}{l}.05 \\
.03 \\
.04 \\
.01\end{array}$ & $\begin{array}{l}.00 \\
.01 \\
.01 \\
.02\end{array}$ & $\begin{array}{l}.00 \\
.00 \\
.01 \\
.02\end{array}$ & $\begin{array}{l}.00 \\
.00 \\
.01 \\
.01\end{array}$ & $\begin{array}{l}.00 \\
.00 \\
.01 \\
.01\end{array}$ & $\begin{array}{l}.00 \\
.00 \\
.01 \\
.02\end{array}$ & $\begin{array}{l}.00 \\
.00 \\
.01 \\
.03\end{array}$ & $\begin{array}{l}.00 \\
.00 \\
.00 \\
.00\end{array}$ & $\begin{array}{l}.01 \\
.00 \\
.01 \\
.00\end{array}$ & $\begin{array}{l}.01 \\
.00 \\
.01 \\
.01\end{array}$ & $\begin{array}{l}.04 \\
.00 \\
.01 \\
.01\end{array}$ & $\begin{array}{l}.03 \\
.00 \\
.02 \\
.02\end{array}$ \\
\hline Group I & $\begin{array}{r}6 \\
2 \\
3 \\
13\end{array}$ & $\begin{array}{r}106 \\
94 \\
81 \\
75\end{array}$ & $\begin{array}{l}.69 \\
.82 \\
.65 \\
.79\end{array}$ & $\begin{array}{l}.57 \\
.63 \\
.39 \\
.64\end{array}$ & $\begin{array}{l}.23 \\
.26 \\
.26 \\
.33\end{array}$ & $\begin{array}{l}.18 \\
.13 \\
.11 \\
.18\end{array}$ & $\begin{array}{l}.03 \\
.05 \\
.04 \\
.06\end{array}$ & $\begin{array}{l}.00 \\
.00 \\
.02 \\
.02\end{array}$ & $\begin{array}{l}.00 \\
.01 \\
.00 \\
.01\end{array}$ & $\begin{array}{l}.00 \\
.00 \\
.01 \\
.01\end{array}$ & $\begin{array}{l}.00 \\
.00 \\
.00 \\
.00\end{array}$ & $\begin{array}{l}.00 \\
.00 \\
.00 \\
.02\end{array}$ & $\begin{array}{l}.01 \\
.00 \\
.00 \\
.01\end{array}$ & $\begin{array}{l}.00 \\
.00 \\
.00 \\
.03\end{array}$ & $\begin{array}{l}.07 \\
.00 \\
.00 \\
.02\end{array}$ & $\begin{array}{l}.03 \\
.00 \\
.01 \\
.04\end{array}$ \\
\hline
\end{tabular}

testing indicated that the groups, days, and interaction effects were all nonsignificant.

The results obtained in the present study demonstrate the efficiency of gradually introducing $S s$ to an $O T$ 30-sec schedule. The gradual introduction procedure provides for immediate and frequent reinforcement of "not pecking" as well as extinction of the pecking response, and this combination seems to be very effective for eliminating the originally reinforced pecking response. Beginning with the second day of OT, all Group G Ss reduced the frequency of pecking drastically, and subsequently, rarely emitted a pecking response. As a result, the OT parameter values were increased steadily and rapidly for these Ss without any noticeable return of the pecking response. Also, no resumption of pecking occurred immediately following the transition to new parameter values.

In contrast, Ss in Group I decreased pecking relatively slowly. This finding could be attributed to the fact that these Ss obtained fewer reinforcements than Group G Ss during the early OT sessions and had fewer occasions for the development of "not pecking." Thus, it is understandable that Group I Ss reduced the frequency of pecking more slowly than did Group G Ss.

Although no systematic observation or recording of behavior during OT was performed, daily observations indicated that all of the Ss developed some specific behavior that bridged (i.e., competed with pecking) the intervals between reinforcements. This behavior almost invariably consisted of turning toward the one-way mirror or crouching in one of the corners of the chamber after the completion of reinforcement. Further, it was noted that these behaviors tended to develop much more readily in the Group G Ss. Admittedly, any attempt to employ the concept of competing behavior to interpret the present findings would be somewhat gratuitous; however, we feel that the possibility is worth investigating.

Since Day 4 was the first complete session on the OT 30-sec schedule for Group G Ss, it is most important to consider the results on this day. Mean transformed response rates for the two groups on Day 4.(.01 vs .15) were significantly different and indicate that Group $G$ Ss had virtually ceased pecking while Group I Ss were still making a considerable number of pecking responses. Thus, the gradual introduction procedure produces a more complete response elimination when the parameter values between groups are initially equated.

Although there were no significant effects in durability testing, none were expected. The extremely durable response elimination shown by all Ss in the present experiment confirms previously obtained findings with OT (Topping et al, 1971b; Uhl \& Garcia,
1969; Uhl \& Sherman, 1971; Zeiler, 1971).

\section{REFERENCES}

ANDERSON, N. H. Comparisons of different populations: Resistance to extinction and transfer. Psychological Review, 1963, 70, 162-179.

LAWRENCE, D. H. The transfer of a discrimination along a continuum. Journal of Comparative \& Physiological Psychology, 1952, 45, 511-516.

SCHLOSBERG, H., \& SOLOMON, R. L. Latency of response in a choice discrimination. Journal of Experimental Psychology, 1943, 33, 22-39.

TERRACE, H. S. Discrimination learning with and without "errors." Journal of the Experimental Analysis of Behavior, 1963 6. $1-27$

TOPPING, J. S., PICKERING; J. W., \& JACKSON, J. A. The differential effects of omission and extinction following DRL pretraining. Psychonomic Science, $1971 \mathrm{a}, 24,137-138$

TOPPING, J. S., PICKERING, I. W. \& JACKSON, J. A. Omission training effects following $V k$ and $F I$ pretraining. Psychonomic Science, $1971 \mathrm{~b}, 24$, 113-114.

TOPPING, J S PICKERING, J W \& JACKSON, J. A. Comparison of omission and extinction following $\mathrm{FR}$ training Psychological Record, 1972, in press.

UHL. C. N., \& GARCIA, E. E. Comparison of omission with cxtinction in response elimination in rats. foumal of Comparative \& Physiological Psvchology. $1969,69,554-562$

UHL, C. N. \& SHERMAN, W. O Comparison of combinations of omission, punishment, and extinction methods in response elimination in rats. Journal of Comparative \& Physiological Psychology. 1971, 74, 59-65.

ZEILER M D. Eliminating behavior with reinforement. Journal of the Experimental Analysis of Behavior, 1971 . $16,401-405$ 